\title{
EDITORIAL OPEN \\ Asthma attacks: how can we reduce the risks?
}

npj Primary Care Respiratory Medicine (2015) 25, 14105; doi:10.1038/npjpcrm.2014.105; published online 8 January 2015

It can be hard for those without asthma-even health professionals - to appreciate how traumatic an asthma attack can be. The mental and physical struggle, the loss of control, and the anxiety engendered, all constitute a deeply unpleasant experience. Unfortunately, for many asthma patients this is a recurring fact of life. If caught early, many attacks can be managed in the community, but the most severe require hospital care, powerful medication and careful monitoring. We are fortunate to have effective medications for reducing the risk. Inhaled corticosteroids (ICS) alone and in combination with longacting $\beta_{2}$-agonists (LABAs), together with other asthma treatments, reduce the risk of attack and have reduced deaths and emergency hospitalisation despite increasing disease prevalence. ${ }^{1}$ Unfortunately, in some countries this trend has stalled. Rates of death, hospitalisation and attacks have shown little decline in the new millennium. The recent UK 'National Review of Asthma Deaths' (NRAD) reported a failure to address avoidable risk factors, and self-management deficiencies, occurring in most asthma deaths. $^{2}$

Why are attacks still so common and devastating? Although some patients have severe, therapy-resistant disease, this applies to only 1 in 20. It is important that these patients are identified and assessed in 'difficult asthma' clinics, as many may be helped by new 'biologic' treatments. ${ }^{3}$ However, as shown in the UK NRAD, the majority of crises occur in those deemed to have milder asthma.

The factors underlying severe attacks frequently relate to patient behaviour, particularly to the pattern of medication use. Self-management education with a personal action plan (with information on why regular treatment is required, actions to be taken as control worsens, and when to seek help) is a firmly evidence-based intervention advocated in guidelines. ${ }^{4}$ Unfortunately, many patients do not receive or practice effective selfmanagement. Non-adherence with 'preventer' medication and over-use of bronchodilators is so common as to be the norm. The link between poor adherence to ICS, ${ }^{5}$ overuse of short-acting bronchodilators, ${ }^{6}$ and adverse outcomes such as deaths and hospitalisation is clearly established, yet these behaviour patterns remain common.

A missing link has been a reliable method for examining inhaler use during attacks. In 1999, Tattersfield et al. ${ }^{7}$ analysed diary data from the FACET study, showing that most attacks do not occur 'out of the blue'-rather, they are characterised by a progressive deterioration in symptoms, lung function and bronchodilator use over a period of about two weeks, accelerating in the final days. There is thus a 'window of opportunity' for recognising worsening asthma and taking action at this crucial time. Recently, the use of an unobtrusive inhaler-monitoring device which can record the timing and number of inhaler actuations is providing valuable insights, particularly during asthma worsening.

In the linked paper, Patel et $a l^{8}{ }^{8}$ describe such a study in patients who subsequently had a severe attack necessitating hospitalisation. This post-hoc analysis from a trial published in $2013,{ }^{9}$ which compared the use of a fixed maintenance dose of budesonide and formoterol (BF) plus salbutamol as the short-acting $\beta_{2}$-agonist (SABA) as-needed reliever, with $\mathrm{BF}$ as single inhaler maintenance and reliever treatment (the SMART approach) in patients at risk of exacerbation, is the first independent, non-pharma funded study of SMART. All patients had experienced an attack in the previous year, and were provided with written self-management plans that included instructions on regular $\mathrm{BF}$ use, use of rescue medication (either BF or SABA), and when to seek medical review when rescue medication exceeded a threshold ( $>8$ additional actuations in the SMART group and $>16$ SABA actuations in the 'standard' group). Although the number of severe attacks was relatively low (22 attendances in 16 patients), the unique and novel nature of these data $^{8}$ make them noteworthy. Hospitalisations for asthma are relatively rare, and to obtain larger numbers would require a much larger cohort which carries logistical issues and inherent biases.

The time course of deteriorating asthma reported by Tattersfield et al. ${ }^{7}$ was confirmed. The levels of bronchodilator use were worryingly high, and significantly, were much higher than patients reported to their doctors. This is understandable, in that patients are attempting to please their doctor and provide the 'right' answer. Indeed, using similar technology, Patel and colleagues have previously shown that bronchodilator over-users tend to under-report, and preventer medication under-users tend to overreport, their inhaler use. ${ }^{10}$ In the current study, ${ }^{8}$ many patients were above the 'threshold' levels of rescue medication use for several days prior to attending, and in some patients the use was astronomic; the median maximum rescue inhaler actuations in $24 \mathrm{~h}$ was 14 (of BF) in the SMART group and 46 (of salbutamol) in the 'standard' group, with peaks of 63 and 95, respectively. Despite this huge bronchodilator use, over half the patients delayed seeking medical attention.

The most intriguing information concerns the pattern of 'maintenance' BF use. It might be expected that maintenance use would increase as symptoms worsened, even in those underusing when stable. However, in a third of patients on 'standard' twice-daily maintenance $\mathrm{BF}$, there was no use whatsoever prior to hospitalisation, despite massive over-use of salbutamol. Variable BF use was observed in others. Even in the context of a clinical trial, with provision of a self-management plan and regular review, some patients were unconvinced that using ICS-containing medication was important even when an attack threatened. As expected, ICS use was higher in SMART, as patients did not have the option of using stand-alone bronchodilators. However, some skipped regular dosing and favoured as-needed use on symptomatic days. Two patients recorded days of no BF use during the build-up of symptoms. In spite of this, the SMART regime ensured greater ICS use during this critical period, which likely explains the exacerbation reduction seen in this group.

Where does this leave us? Two important points emerge. Firstly, persuading some patients that they need to take regular ICS (even as a combination inhaler) is an ongoing challenge. All participants had previously had an attack, were given information (i.e., had been educated), and had a written action plan. Yet the message that maintenance treatment is crucial in reducing attacks had clearly not got through. Why? Is it that the information was misunderstood or unconvincing? Or is education alone insufficient to change behaviour? Attitudes, priorities, fears and preferences may override factual knowledge, and strategies that address these factors may be more successful. Another approach uses treatments that anticipate and accommodate 'usual' patient behaviour. Examples include combination treatments, biologicals or treatments that are injected and/or involve infrequent dosing. 
However, all patients require a self-management strategy when an attack threatens. Patel et al. ${ }^{8}$ here provide evidence that the 'SMART' approach is more effective than fixed preventer with SABA as-needed, at least in at-risk patients. GINA 2014 and other strategy documents highlight the need to quantify 'risk' and address factors associated with increased risk. Better risk stratification, including monitoring of patterns of medication use before and after attacks, most simply by refill prescription counting, would be a good first step.

Secondly, we need to get better at convincing high-risk patients that they need to contact us when things start going wrong. The huge over-use of bronchodilators without seeking help is alarming and is only too consistent with the NRAD data, where almost half of the patients who died called for help too late.

The focus in asthma research is often on newer and more effective treatments. Studies like this one ${ }^{8}$ show us how far we have to go in using the treatments we have to best advantage, and the need to empower patients to achieve effective self-management.

\section{COMPETING INTERESTS}

Neither MT nor any member of his close family has any shares in pharmaceutical companies. In the last 3 years he has received speaker's honoraria for speaking at sponsored meetings or satellite symposia at conferences from the following companies marketing respiratory and allergy products: Aerocrine, Astra Zeneca, Boehringer Inglehiem, GSK, MSD, Teva. He has received honoraria for attending advisory panels with; Aerocrine, Almirall, Astra Zeneca, BI, Chiesi, GSK, MSD, Novartis. He has received sponsorship to attend international scientific meetings from: GSK, Astra Zeneca, Mundipharma. He has received funding for research projects from: GSK, Almirall. He is chief medical adviser to the charity Asthma UK, a member of the BTS SIGN Asthma guideline group and the NICE Asthma guideline group.

EB reports personal fees for consulting and advisory board membership from Actelion, Almirall, AstraZeneca, Boehringer Ingelheim, and Hoffman la Roche; personal fees for advisory board membership from ALK-Abello, Chiesi, Elevation Pharma, Forest, Glaxo SmithKline, Napp Pharma, Navigant Consulting, Novartis, Pfizer, IMS Consulting Group, Takeda, and ICON; personal fees for lectures from AstraZeneca, Boehringer Ingelheim, Chiesi, Glaxo SmithKline, Merck, Novartis, Pfizer and Takeda; personal fees for educational materials from PeerVoice and Indegene; and grants to his institution for participation in clinical trials sponsored by Actelion, Aeras, Almirall, AstraZeneca, Boehringer Ingelheim, Cephalon, Chiesi, Glaxo SmithKline, Hoffman la Roche, Merck, Nycomed, Takeda, TEVA and Sanofi-Aventis outside the submitted work. He is a member of the Board of the Global Initiative for
Asthma (GINA). Neither he nor any member of his close family has shares in a pharmaceutical company.

Mike Thomas ${ }^{1}$ and Eric Bateman ${ }^{2}$

${ }^{1}$ Department of Primary Care Research, University of Southampton and Aldermoor Health Centre, Southampton, UK and

${ }^{2}$ Division of Pulmonology, Department of Medicine, University of Cape Town, Cape Town, Republic of South Africa Correspondence: M Thomas (D.M.Thomas@soton.ac.uk)

\section{REFERENCES}

1 Ducharme FM, Ni Chroinin M, Greenstone I, Lasserson TJ. Addition of long-acting beta2-agonists to inhaled corticosteroids versus same dose inhaled corticosteroids for chronic asthma in adults and children. Cochrane Database Syst Rev 2010; (5): CD005535.

2 Royal College of Physicians. Why Asthma Still Kills: the National Review of Asthma Deaths (NRAD) Confidential Enquiry Report. RCP: London, 2014.

3 Chung KF, Wenzel SE, Brozek JL, Bush A, Castro M, Sterk PJ et al. International ERS/ ATS guidelines on definition, evaluation and treatment of severe asthma. Eur Respir J 2014; 43: 343-373.

4 Gibson PG, Powell H, Wilson A, Abramson MJ, Haywood P, Bauman A et al. Selfmanagement education and regular practitioner review for adults with asthma. Cochrane Database Syst Rev 2002; (3): CD001117.

5 Bourbeau J, Ernst P, Cockcoft D, Suissa S. Inhaled corticosteroids and hospitalisation due to exacerbation of COPD. Eur Respir J 2003; 22: 286-289.

6 Suissa S, Blais L, Ernst P. Patterns of increasing beta-agonist use and the risk of fatal or near-fatal asthma. Eur Respir J 1994; 7: 1602-1609.

7 Tattersfield AE, Postma DS, Barnes PJ, Svensson K, Bauer CA, O'Byrne PM et al. Exacerbations of asthma: a descriptive study of 425 severe exacerbations. The FACET International Study Group. Am J Respir Crit Care Med 1999; 160: 594-599.

8 Patel M, Pilcher J, Hancox RJ, Sheahan D, Pritchard A, Braithwaite I et al. The use of $\beta_{2}$-agonist therapy before hospital attendance for severe asthma exacerbations: a post-hoc analysis. npj Prim Care Respir Med 2015; 25: 14099.

9 Patel M, Pilcher J, Pritchard A, Perrin K, Travers J, Shaw D et al. Efficacy and safety of maintenance and reliever combination budesonide-formoterol inhaler in patients with asthma at risk of severe exacerbations: a randomised controlled trial. Lancet Respir Med 2013; 1: 32-42.

10 Patel M, Perrin K, Pritchard A, Williams M, Wijesinghe M, Weatherall M et al. Accuracy of patient self-report as a measure of inhaled asthma medication use. Respirology 2013; 18: 546-552.

\footnotetext{
(c) (i) $(-)$ This work is licensed under a Creative Commons AttributionNonCommercial-NoDerivatives 4.0 International License. The images or other third party material in this article are included in the article's Creative Commons license, unless indicated otherwise in the credit line; if the material is not included under the Creative Commons license, users will need to obtain permission from the license holder to reproduce the material. To view a copy of this license, visit http:// creativecommons.org/licenses/by-nc-nd/4.0/
} 